\title{
CAPÍTULO 17: UTILIZAÇ̃̃O DE ESPAÇO NÃO FORMAL NO ENSINO DE QUÍMICA AMBIENTAL: VISITAÇÃO AO PARQUE ESTADUAL DO UTINGA, BELÉM, PARÁ
}

\author{
CAPÍTULO 17: USO DEL ESPACIO NO FORMAL EN LA ENSEÑANZA DE LA \\ QUÍMICA AMBIENTAL: VISITA AL PARQUE ESTATAL DE UTINGA, BELÉM, \\ PARÁ
}

\section{CHAPTER 17: USE OF NON-FORMAL SPACE IN TEACHING ENVIRONMENTAL CHEMISTRY: VISITING TO UTINGA STATE PARK, BELÉM, PARÁ}

\author{
Ivan Carlos da Costa Barbosa ${ }^{1}$
}

DOI: https://doi.org/10.31692/978-65-88970-05-8.215-218

\section{INTRODUÇÃO}

Nos dias atuais entende-se que o processo educacional pode ser concebido em diferentes espaços, os quais podem ser denominados de espaço formal, espaço não formal e espaço informal de educação (SMITH, 2001). Ainda segundo o autor, o espaço formal é constituído pelo tradicionalmente lugar conhecido desde o início do estudo (ensino primário) até a finalização (universidade) de uma pessoa, ou seja, o denominado "sistema de ensino"; o espaço informal é caracterizado por um processo constante ao longo da vida de uma pessoa e que gera atitudes, valores, habilidades e conhecimentos nas situações do cotidiano seja em familía, entre amigos, na rua, etc; e o espaço não formal é representado por qualquer atividade educativa planejada fora do sistema de ensino formal e que apresenta objetivos específicos de aprendizagem.

De acordo com Lobo et al. (2017), a captação realizada pelos sentidos gera processos que necessitam de uma significação, possibilitando a formação de ligações entre os objetos percebidos e a ampliação da percepção destes. Para os espaços não formais, segundo Lobo et al. (2017) "a percepção destes espaços descortina diversificadas possibilidades de desfechos de experiências, que vão além do cumprimento de um roteiro guiado ou de uma simples visita contemplativa".

Conforme Mozeto e Jardim (2002), a Química Ambiental (QA), como uma área clássica da Química, pode receber diferentes conceituações. De maneira geral, a QA processos químicos que ocorrem na natureza, sejam eles naturais ou ainda causados pelo homem, e que comprometem a saúde humana e a saúde do planeta como um todo". Paula et al.

\footnotetext{
${ }^{1}$ Mestrado em Química, Universidade Federal Rural da Amazônia, ivan.barbosa@ufra.edu.br
} 
(2015) comentam acerca da importância de todos, e não apenas um indivído, ter responsabilidade sobre a preservação da biodiversidade do planela. Além de discutir o papel da escola como "a principal formadora de cidadãos brasileiros conscientes que venham agir de modo responsável na sociedade em que estão inseridos" (PAULA et al., 2015).

O Parque Estadual do Utinga (PEUt), com um total de 1.393,088 ha, representa uma Unidade de Conservação (UC) de proteção integral, um patrimônio natural e paisagístico do Estado do Pará e fica localizado dentro da Área de Proteção Ambiental (APA Belém pertencente ao municípios de Belém e Ananindeua). Sua criação em 1993 teve como objetivo proteger os mananciais de água dos lagos Bolonha e Água Preta que fornecem água para os moradores da capital Belém e municíos adjacentes (SILVA; SILVA, 2017).

Diante dessa perspectiva, o Parque Estadual do Utinga (PEUt) foi utilizado como espaço não formal no ensino de Química Ambiental para um estudo observacional acerca da utilização do parque pela população e a sua relação com o ecossistema natural. Por fim, foi gerado um debate oral acerca das percepções realizadas por alunos do Curso de Graduação em Licenciatura em Biologia do Programa Nacional de Formação de Professores (PARFOR), ofertado pela Universidade Federal Rural da Amazônia (UFRA) campus Belém, durante a visita realizada em dia e horário de alta circulação de pessoas (sábado no horário de 8 às 10h).

\section{RELATO DE EXPERIÊNCIA}

Segundo o site do Instituto de Desenvolvimento Florestal e da Biodiversidade do Estado do Pará - Ideflor-bio (2020), que realizada a administração, o PEUt está inserido na Região Metropolitana de Belém que é caracterizada por uma absorção migratório forte nos últimos anos e gerou uma ocupação urbana desordenada proveniente deste incremento populacional. Nos últimos anos o PEUt é aberto para visitação diária ao longo do dia. No local os visitantes podem caminhar, correr, andar de bicicleta e/ou de patins, atividades de ecoturismo, realizar exercícios contemplativos de beleza cênica e meditativos.

No dia 06 de julho de 2019, sábado por volta das 8h, os alunos da disciplina se reuniram na entrada do PEUt para receberem as orientações do professor da disciplina de Química Ambiental acerca do objetivo da visita. No primeiro momento, todos caminharam por alguns minutos observando a utilização do parque por parte dos visitantes. Conforme observações realizadas foi possível constatar pelos alunos: pessoas caminhando e pedalando bicicletas (individuais e coletivas) com roupas apropriadas e aparentemente com uso de protetor solar; pessoas realizando exercícios físicos na via pavimentada do parque; e, pessoas realizando 
ecoturismo através do uso das trilhas (caminhada e pedalada) na área de vegetação e tirolesa. A Figura 1 apresenta exemplificações destas atividades no parque.

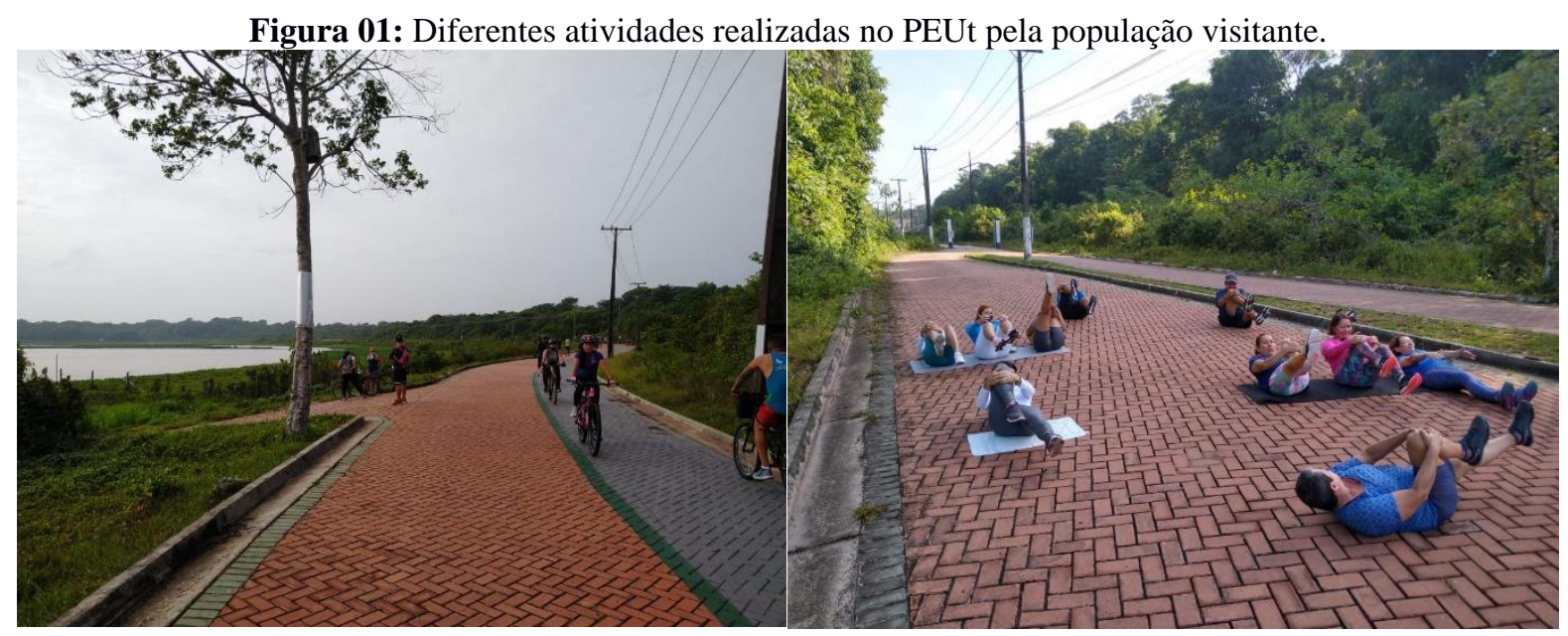

Fonte: Própria (2019).

No segundo momento foi realizada uma reflexão acerca da relação entre estas atividades humanas realizadas no parque e o respeito a biodiversidade presente. Os alunos relataram avaliar como positiva a preservação e uso do espaço em conformidade com a natureza presente.

A biodiversidade abundante no PEUt é formada especificamente por florestas de terra firme frequentes em regiões internas e elevadas do local, com solo tipicamente argiloso e úmido, vegetação de palmeiras, ervas, epífitas, lianas, arvoredos e árvores (IDEFLOR-BIO, 2020). Os autores ainda citam a ocorrência, às margens dos Lagos Bolonha e Água Preta, de florestas de igapó na mata, terreno baixo e úmido, e, por fim, floresta ombrófila densa, distribuída por diversas áreas ao longo do Parque

No terceiro e último momento os alunos e o professor da disciplina se reunião para debater oralmente sobre a importância da preservação do parque associada ao seu uso sustentável por parte da população. Uma das primeiras considerações realizada pelos alunos foi sobre a importância de se preservar tanto os fatores bióticos (animais e vegetação) como os abióticos (água, ar e solo). Outra consideração feita pela turma foi sobre a necessidade da realização de campanhas educativas para a população visitante do parque e a utilização do parque por instituições de ensino infantil, fundamental e médio para ações de educação ambiental. De acordo com Soler e Dias (2016), “a Educação Ambiental tem sido apontada como importante ferramenta para enfrentar a crise ecológica, podendo ensejar mudanças no atual paradigma hostil à vida". 


\section{CONCLUSÕES}

É possível concluir que o Paque Estadual do Utinga pode ser facilmente utilizado como um excelente espaço não formal de ensino. Diversas características contribuiem para a sua utilização com: localizado em área de fácil acesso, entrada gratuita, horário de funcionamento amplo (6h às 17h), espaço amplo com presença de biodiversidade, acessibilidade para portadores de necessidades especiais, serviços essenciais presentes (por exemplo, lanchonetes, restaurante, banheiros e alugel de bicicletas) e infraestutura adequada para as diversas atividades realizadas.

Com todos estes benécios, o PEUt se torna um excelente espaço para discussões sobre a relação homem - natureza e a importância urgente do estabelecimento de uma relação sustentável para a sobrevivência de ambos os atores. Os alunos da disciplina Química Ambiental puderam refletir sobre estes aspectos, observando quais pontos poderiam ser melhorados no parque (implantação de mais lixeiras e ações de educação ambiental) para uma otimização do seu uso.

\section{REFERÊNCIAS}

INSTITUTO DE DESENVOLVIMENTO FLORESTAL E DA BIODIVERSIDADE DO ESTADO DO PARÁ - IDEFLOR-BIO. Parque Estadual do Utinga - PEUt, c2018. Disponível em: <https://ideflorbio.pa.gov.br/unidades-de-conservacao/regiao-administrativade-belem/\%20parque-estadual-do-utinga/>. Acessado em: 17 de set de 2020.

LOBO, H. B.; TRINDADE, D. S. A.; CORDOVIL, R. V. Ensino de Ciências em espaços não formais à luz da epistemologia bachelardiana. Revista REAMEC, Cuiabá - MT, v. 5, n. 2, 2017.

MOZETO, A. A.; JARDIM, W. F. A Química Ambiental no Brasil. Química Nova, v. 25, Supl. 1, p. 7-11, 2002.

PAUlA, T. V.; SOUZA, E. V. P.; SILVA, T. G. N.; SILVA, D. M.; RIBEIRO, M. E. N. P Proposta educativa utilizando o jogo RPG Maker: estratégia de conscientização e de aprendizagem da Química Ambiental. HOLOS, Ano 31, v. 8, 2015.

SMITH, M. K. 'What is non-formal education?'. The encyclopedia of informal education. 2001.

SILVA, J. B.; SILVA, M. C. P. Educação Ambiental aplicada em Parque Estadual no Pará: uma perspectiva crítica. Revista Geográfica Acadêmica, v.11, n.1, 2017.

SOLER, A.; DIAS, E. A. A educação ambiental na crise ecológica contemporânea. Acesso Livre, n. 5, jan.-jun., 2016. 